\title{
FAITH AS AN EPISTEMIC DISPOSITION
}

\author{
T. RYAN BYERLY
}

Baylor University

\begin{abstract}
This paper presents and defends a model of religious faith as an epistemic disposition. According to the model, religious faith is a disposition to take certain doxastic attitudes toward propositions of religious significance upon entertaining certain mental states. Three distinct advantages of the model are advanced. First, the model allows for religious faith to explain the presence and epistemic appropriateness of religious belief. Second, the model accommodates a variety of historically significant perspectives concerning the relationships between faith and evidence, faith and volition, and faith and doubt. And, finally, the model offers an appealing account of what unifies religious faith with other kinds of faith.
\end{abstract}

\section{INTRODUCTION}

In this paper, I will explicate and defend a model of religious faith according to which religious faith is an example of what I call an epistemic disposition. In the first section, I explain what epistemic dispositions are and say how in very general terms religious faith might be understood as one of these dispositions. In sections two through four I highlight some of the central advantages of modelling religious faith in this way. Section two focuses on the present model's ability to accommodate the apparent explanatory priority of religious faith to religious belief. It shows how on the present model it could be that a person holds religious beliefs because she has religious faith, and how on the present model it could be that a person's holding of religious beliefs might be epistemically appropriate because of her religious faith. Section three focuses on the present model's ability to accommodate a variety of historically significant 
perspectives concerning the relationships between faith and evidence, faith and volition, and faith and doubt. It is a boon of the present model that it does not rule out historically significant and opposing answers to questions about these relationships. Finally, I conclude the paper by reflecting on the relationship between religious faith modelled in the way proposed here and other kinds of faith. I show that the model of religious faith proposed here might be modified so as to yield attractive models of faith in other domains as well, thereby yielding an explanation of what unifies our talk of faith in these various areas.

\section{EPISTEMIC DISPOSITIONS AND A GENERAL MODEL}

Begin with the question of what an epistemic disposition is. To find an answer, we need to say something about dispositions in general, since epistemic dispositions are just one sub-class of dispositions in general. I won't offer an analysis of what a disposition is, however. For one thing, I'm sceptical that this is possible. Attempts to analyse dispositions are notoriously suspect. ${ }^{1}$ But, for another, we don't need an analysis of dispositions here to find a way of distinguishing epistemic dispositions from other dispositions which aren't epistemic dispositions.

All we need, instead, is a handle on what Robert Audi (1994) calls "realization conditions" and "constitutive manifestations". To see what these two elements involve, consider the paradigm instance of fragility. When we ascribe the disposition of fragility to a glass, we are saying that there is something about the glass's nature which makes it likely under certain conditions that the glass will break. The realization conditions of the glass's fragility will be conditions involving a certain amount of pressure and the constitutive manifestations of the disposition will be behaviours involving shattering. Importantly, these realization conditions and constitutive manifestations are partially constitutive of the disposition of fragility. A disposition whose constitutive manifestations don't involve shattering or breaking in any way is just not the disposition of fragility. Dispositions, then, can be partially individuated by their realization conditions and constitutive manifestations.

And, indeed, we can individuate epistemic dispositions in just this way. What makes a disposition an epistemic disposition is that there are certain restrictions on its realization conditions and constitutive

\footnotetext{
${ }^{1}$ See the review of such attempts in (Fara 2006).
} 
manifestations. The realization conditions of epistemic dispositions will be sets of mental states - sets of beliefs, experiences, emotions, and so on. The constitutive manifestations of epistemic dispositions will be doxastic attitudes like belief, disbelief, suspension of judgment, and perhaps other degreed attitudes if such there be. ${ }^{2}$ Thus, epistemic dispositions will be dispositions in the presence of certain mental states to take certain doxastic attitudes.

I call them epistemic dispositions because they are dispositions having to do with the way we function as believers. Typically, the way that we navigate our experience of the world is by gathering evidence and responding to it in a way that makes sense from our perspective. Our gathering of evidence involves us coming to host mental states like beliefs, experiences and so on. ${ }^{3}$ And, the way we respond to this evidence is by taking those attitudes that these mental states dispose us to take.

Some examples may help. One example of an epistemic disposition would be my disposition to believe I am seeing a black cat in the presence of my having visual experiences as of a black cat. There are a whole range of such visual experiences which might trigger - which might act as realization conditions for - this disposition. They are all experiences like those I would have were I to see a black cat of some kind. And, because I have the aforementioned disposition, when I have these kinds of experiences, I tend to believe I am seeing a black cat. If I want to know whether there's a black cat around, I'll gather evidence by looking around and then I'll respond to the evidence I gather by taking those attitudes my gathered evidence disposes me to take. Here's another example: I have a disposition, upon feeling horrified or disgusted by a situation, to believe that something has gone morally amiss. When contemplating a situation engenders these emotions in me, I tend to think that there is something morally wrong with the contemplated situation. If I want to know what to think about whether there is something wrong about a given scenario,

${ }^{2}$ I am thinking here of degrees of belief. For a brief overview of degrees of belief see the discussion of subjective probability in (Hajek 2009) or the various pieces in (Huber and Schmidt-Petri 2009).

${ }^{3}$ I do not intend here to make any substantive claim about the nature of evidence. It is perhaps easiest to think of evidence on my view as consisting in mental states, along the lines proposed in Conee and Feldman (2008). But, if someone prefers to think of evidence as consisting in propositions (like, e.g., [Williamson 2000]), I could distinguish between the evidence there is - which is a body of propositions - and those mental states whereby someone comes to possess that evidence - experiences, beliefs, and so on. 
one way I can check is by seeing if I respond to the scenario with one of the aforementioned emotions and then following the emotion to the attitude toward which it leads me. A third example would be my disposition to believe a proposition $\mathrm{q}$ in the presence of believing a proposition $\mathrm{p}$ and a proposition if $\mathrm{p}$ then $\mathrm{q}$. When I come to believe $\mathrm{p}$ and to believe if $\mathrm{p}$ then $\mathrm{q}$, I tend to also come to believe q. Both this and the foregoing examples were examples of epistemic dispositions because they are all examples of dispositions whose realization conditions are sets of mental states and whose constitutive manifestations are doxastic attitudes.

Now my proposal here is that we understand religious faith as an epistemic disposition of this sort. Very generally, religious faith will be a disposition in the presence of certain mental states to take certain doxastic attitudes toward propositions with religiously significant content. I won't specify here which precise mental states must serve as the realization conditions of faith, which precise propositions with religiously significant content must be the propositions a person of faith is disposed take doxastic attitudes toward, or which doxastic attitudes the person of faith must be disposed to take toward these propositions. All I will say is that the doxastic attitudes which serve as the constitutive manifestations of faith will include what we typically refer to as "religious beliefs". ${ }^{4}$ Thus, on the present general model, faith is a disposition to hold religious beliefs and perhaps other doxastic attitudes toward propositions of religious significance in the presence of certain mental states. Call this the epistemic disposition model. I will discuss options for filling in the details of this general model in section three. But, before doing so, I want to remark on the present model's ability to accommodate the explanatory priority of religious faith to religious belief.

\section{THE EXPLANATORY PRIORITY OF RELIGIOUS FAITH TO RELIGIOUS BELIEF}

It is not uncommon for people to talk as if religious faith explains something significant about religious belief. I'll discuss two cases here and show how the epistemic disposition model accommodates this idea at face value better than do alternative models.

\footnotetext{
${ }^{4}$ By calling them the attitudes we typically refer to as religious beliefs, I intend to leave it an open question whether they are beliefs or something else. When I talk of "religious belief" in the following section, it is to be understood in this same way - whatever attitude it is that we are talking about when we use appropriately the title "religious belief".
} 
First, consider the following conversation:

A: B, why do you believe all this stuff about Jesus and the Holy Spirit and the Virgin Mary? It's not like you think there is overwhelming evidence for all this, right? But you really do believe it nonetheless.

B: That's right, A. I don't believe because I think the evidence is overwhelming. I believe because I have faith. If you're going to believe, you'll have to have faith, too.

Here it sounds as if $B$ is suggesting that the explanation for why he holds certain religious beliefs is that B has faith. Indeed, it may be that $\mathrm{B}$ is suggesting that religious faith provides a contrastive reason here. B believes, and A does not believe, because B has faith and A doesn't. Religious faith is brought forward as an explanation for the presence of religious belief.

Here's a second case:

A: Why should a person believe all those things you do? I'm not just asking why you do believe them, but why is believing those things the appropriate thing to do?

B: Here again, the answer is faith. A person who has faith should believe these things. Maybe someone who doesn't have faith shouldn't. But if you have faith, it is of course appropriate for you to believe.

This time religious faith is again invoked to explain something about religious belief. It is invoked to explain the epistemic appropriateness or justification of religious belief. Religious beliefs are ones the person of faith should have. They are ones it is appropriate for the person of faith to have. Religious faith is invoked to explain the positive normative epistemic status of religious belief. ${ }^{5}$

Neither of the above conversations is uncommon. It is a quite ordinary occurrence for people to appeal to the explanatory priority of faith to belief in this way. But if we take these claims at face value, then the model of faith proposed in the previous section has significant advantages over many other contemporary models. For, many contemporary models simply identify faith with religious belief or with some attitude which

\footnotetext{
${ }^{5}$ I'm not trying to insist on any particular epistemic property here. When I talk of "appropriateness" or "justification" or "what should be believed" I am simply thinking of the belief as having some positive normative status. Thus, B's claim is that faith explains the positive normative status (whatever it is) of religious belief.
} 
stands in for religious belief. ${ }^{6}$ But identifying these two will surely fail to make sense of the explanatory priority of one to the other.

To see this, suppose that we identify faith with religious belief. Then in the first conversation, what B is saying is that he believes the things he believes because he does. This is hardly an explanation. Rather, it sounds like a refusal to offer an explanation. Even worse, this view has B reporting a tautology to A: if A is going to believe, he will have to believe. It could be that this is what B is doing. But, surely understanding his speech in this way is not to take him at face value. At face value, $B$ really does offer an explanation for why he believes, and he tells A something of significance when he tells A that if he is going to believe, he will have to have faith. Thus, identifying faith with religious belief will not allow us to take B's talk in the first case at face value.

Nor will it allow us to take B's talk in the second case at face value. If we identify faith and belief in the second case, then B is saying that the person who holds religious beliefs should hold those beliefs because she does. There are some epistemologists who have flirted with the idea that believing a proposition gives a person some reason to believe that proposition, ${ }^{7}$ but it is surely a bit much to say that a person ought to believe something because she does! B seems to be claiming a more favourable epistemic status for religious belief that than which it might receive by simply being had. If we want to take $B$ at face value, then we cannot identify faith with religious belief.

Models which identify religious faith with religious belief or with some stand-in for religious belief fail to treat these exchanges at face value, then. ${ }^{8}$ But modelling faith as an epistemic disposition along the

${ }^{6}$ Swinburne (2005) discusses a model of faith where faith consists in beliefs in propositions with religiously significant content. He calls the model the "Thomist" model. An example of a model which takes faith as something short of belief is Alston's (1996) acceptance model.

${ }^{7}$ See for instance (McGrath 2007), who defends this view as the heart of "epistemic conservatism". Others have resisted McGrath's sort of conservatism, arguing for more limited varieties (see, e.g., [Foley 1983], [Kvanvig 1989], [Vahid 2004]).

${ }^{8}$ A similar point applies to Bishop's (2007) doxastic venture model of faith. For, on his view, religious faith is a commitment to employing certain believed religious propositions in one's practical reasoning, while recognizing that these propositions aren't adequately supported by one's evidence. But this view will not allow us to make sense of the explanatory priority of faith to religious belief. If anything, the order of explanation will go the other way around. Faith on this model won't be able to explain the presence or appropriateness of religious belief. It only explains why persons who already have 
lines proposed in the previous section can make good sense of both exchanges. Indeed, it can explain how the claims about the explanatory priority of faith may be quite correct.

Take first the claim that religious faith explains the presence of religious belief. If we understand faith as an epistemic disposition, then this claim is quite easy to make sense of. Why do some persons hold religious beliefs while others do not? The answer is faith. Some persons are disposed to have these beliefs in the presence of certain mental states and others are not. When those who are disposed in this way host the requisite mental states, they tend to hold the religious beliefs in question. They hold them because of the way they are disposed. They hold them because of their faith. So, the present model can make sense of the claim that religious faith explains the presence of religious belief.

It can also make sense of the claim that religious faith explains the appropriateness of religious belief. To see this, we need to reflect briefly on how epistemic dispositions more generally contribute to the appropriateness of beliefs. The examples of section one are a helpful guide here. Recall the example of my disposition in the presence of visual experiences of black cats to believe I am seeing a black cat. How can this disposition contribute to the appropriateness of my beliefs? As a first pass, it seems that it can do so by being that by virtue of which my mental states incline me to believe that I'm seeing a black cat. For instance, imagine that I have this disposition and that I come to have an experience as of seeing a black cat. My experience then inclines me, by virtue of my disposition, to believe that I'm seeing a black cat. And nothing else prevents me from being so inclined. In such a case, it seems plausible that believing that I'm seeing a black cat is epistemically appropriate, and that my disposition has contributed to its appropriateness.

More generally, a thesis like the following seems quite attractive:

(D) If a subject $S$ 's mental states $M$ incline $S$ to take attitude $A$ by virtue of a disposition $\mathrm{D}$ to take $\mathrm{A}$ in the presence of states like $\mathrm{M}$, and none of S's other mental states prevent this inclination, ${ }^{9}$ then it is appropriate for $\mathrm{S}$ to take attitude $\mathrm{A}$.

religious beliefs deliberate and behave in a certain way. Thus, the epistemic disposition model discussed here has the same advantage over Bishop's doxastic venture model that it has over the Thomistic and acceptance models.

${ }^{9}$ I add this clause because of cases where one's evidence causes one to have a prima facie, but not an ultima facie inclination to take a certain attitude. In such cases, though 
If thesis $\mathrm{D}$ or something much like it is true, then the epistemic disposition model of faith can explain quite well how religious faith could explain the appropriateness of religious belief. For, it could be that the religious believer comes to hold her beliefs when, by virtue of her faith, her mental states incline her to take these beliefs. That is, the religious believer has a disposition in the presence of certain mental states to hold certain religious beliefs (i.e., her faith), and when she comes to host these mental states they incline her toward these religious beliefs by virtue of this disposition. When this occurs, thesis $\mathrm{D}$ says that holding these religious beliefs is appropriate. And, part of the explanation for why they are appropriate is her faith - her disposition to hold them in the presence of those mental states which have so inclined her to these beliefs.

So, if thesis D or something much like it is true, then the epistemic disposition model of faith can explain how religious faith explains the appropriateness of religious belief. B's remark may be quite accurate: faith makes a difference to the appropriateness of religious belief. But, is $\mathrm{D}$ or something like it true? I cannot argue at great length here that it is. But let me offer a brief defence.

The primary reason I know of for accepting a thesis like D is its explanatory power. Specifically, thesis D offers a unified explanation of diverse but plausible cases where beliefs have positive normative epistemic status. I'll talk here about three such cases - cases involving natural and artificial signs, cases involving moral emotions, and cases involving intuition.

Start with cases involving natural and artificial signs. The distinction between natural and artificial signs goes back at least as far as Thomas Reid. ${ }^{10}$ An artificial sign is a sign which signifies what it does in virtue of some tacit agreement among people, while a natural sign signifies what it does in some other way. For instance, the word "pigs" artificially signifies pigs, while smoke naturally signifies fire.

one is disposed to take the relevant attitude in the presence of some of her evidence, other evidence of hers prevents her from being so inclined in light of all of her evidence. For instance, when I look at the Mueller-Lyer lines, my experience gives me a prima facie inclination to believe that the lines are of different lengths. But, since I know better, it does not give me an ultima facie inclination to believe they are different lengths. My knowledge prevents me from being inclined in light of all of my evidence to believe the lines are of different length. Thus, I add this clause to D so that D will not imply that in this sort of case I am justified in believing that which I am only prima facie inclined to believe.

${ }^{10}$ See (Yaffe and Nichols 2009), who say the distinction goes back further. 
These signs are thought by Reid and others to play an important role in determining what is appropriate for a person to believe. Consider some examples. It might, by virtue of my seeing smoke, become epistemically appropriate for me to believe that there is a fire. Or, it might, by virtue of my seeing the sentence "The democrats lost four seats in the house," become epistemically appropriate for me to believe that there is a sentence reporting that the democrats lost four seats in the house. Of course, this need not be so. It is equally possible that I have these experiences and that the aforementioned beliefs not be appropriate.

A thesis like D can help to explain the difference between those cases where my experiences make the corresponding beliefs appropriate and those cases where they do not. In those cases where my experience of smoke does make it appropriate for me to believe that there is a fire it is because my experience, by virtue of my disposition in the presence of like experiences to believe that there is a fire, inclines me to believe that there is a fire. In those cases where my experience of the sentence makes it appropriate for me to believe that there is a sentence reporting that the democrats lost four seats, it is because my experience, by virtue of my disposition in the presence of like experiences to believe that there is a sentence with such contents, has inclined me to believe that I just read a sentence with such contents. By contrast, where I have these experiences but the same attitudes are not appropriate, it may be because I do not have the relevant dispositions working in the same way.

D also helps to explain the epistemic appropriateness of believing certain moral claims on the basis of moral emotions. One way this may go is as follows. Suppose I consider the claim that torturing babies for fun is morally wrong. I reflect on the claim, I imagine scenarios involving this sort of harsh treatment, and I have a feeling of disgust or horror as a result. Further, I have a disposition when I have such experiences to believe that what I'm contemplating is morally wrong. So, as I contemplate the envisioned scenario and react with disgust or horror to it, this inclines me by virtue of my aforementioned disposition to believe that torturing babies for fun is morally wrong. In this way, thesis D can help to explain how certain moral beliefs might be epistemically appropriate as well. They are appropriate because some mental state like a moral emotion inclines the subject to these beliefs by virtue of a disposition she has in the presence of such emotions to take these attitudes.

Finally, thesis D also allows for a powerful explanation of the nature and justificatory power of intuition. Consider, for instance, the intuition 
that the fact that I will teach class tomorrow doesn't explain why I have the evidence I currently do concerning my teaching tomorrow. For me, this intuition is very powerful. It is intuitively clear to me that what explains why I have the evidence I do about whether I will teach tomorrow is a body of present and past facts, rather than the fact that I will in fact teach tomorrow. Now, I might contemplate the proposition that my teaching tomorrow does explain why I have the evidence I currently do and in light of this intuition, come to disbelieve this proposition. And, plausibly, my doing so would be epistemically appropriate in light of the force of my intuition.

Thesis D can offer an explanation for why this is so. For, reports about intuitions are plausibly understood as reports about epistemic dispositions. My intuition that my teaching class tomorrow doesn't explain my current evidence is just a disposition to disbelieve that my teaching tomorrow does explain my current evidence upon considering the claim that it does. Or, perhaps, it is a disposition, upon considering this proposition in light of a grasp of certain conceptual connections, to disbelieve that the teaching explains the evidence. Thus, thesis $\mathrm{D}$ can explain how intuition can make beliefs epistemically appropriate since intuition is just one particularly forceful kind of disposition. ${ }^{11}$

Indeed, thesis D provides a unified account of these difficult-toexplain yet plausible cases of justification. Each of the foregoing types of cases - the cases involving natural and artificial signs, the cases involving moral emotions, and the cases involving intuition - is a plausible case of epistemically appropriate belief. Thesis D offers a unified explanation for why these attitudes are epistemically appropriate. These attitudes are appropriate because some mental state or states of the subjects incline them to take these attitudes by virtue of a disposition they have in the presence of such mental states to take these attitudes. In the case of natural and acquired signs, an experience does this; in the case of moral belief an emotion does this, and in the case of intuition a thought or episode of considering along with an adequate grasp of certain concepts does this. In all three cases, then, $\mathrm{D}$ provides a powerful explanation for how it is that the subjects have the epistemic properties we take them to have. Thus, thesis D has a great deal of explanatory power. ${ }^{12}$

\footnotetext{
${ }^{11}$ Similar accounts of intuition are offered by (Sosa 2007a) and (Swinburne 2001).

${ }^{12}$ Of course, in order to have a fully satisfying inference to the best explanation, I need to show that other available explanations of the same data are either not equally or more
} 
This is not to say that there are no objections to $\mathrm{D}$. The internalist might object to $\mathrm{D}$ on the basis that it allows dispositions of which the subject is unaware to contribute to what is epistemically appropriate to believe. ${ }^{13}$ But there is an easy fix to $\mathrm{D}$ for this - just restrict the dispositions in $\mathrm{D}$ to ones of which the subject is aware. So long as a subject can be aware of her faith - which B's remarks above seem to make plausible - this modified version of $\mathrm{D}$ would still lend credence to the claim that religious faith could explain the epistemic appropriateness of religious belief. Another objection might be that $\mathrm{D}$ allows weird or even seemingly irrational dispositions to contribute to what is epistemically appropriate to believe. Again, we might modify D so that only reliable or virtuous dispositions can contribute to epistemic appropriateness. ${ }^{14}$ If it can be defended that faith is a reliable or virtuous disposition - theses which persons of faith have found attractive ${ }^{15}$ - then again this will make perfectly intelligible B's claim that religious faith explains the appropriateness of religious belief. Or, we might instead reply that these seemingly irrational dispositions contribute to epistemic appropriateness, but that there are more valuable epistemic properties beyond this appropriateness. For instance, it might be that when a person believes in accordance with the dispositions she has (whether virtuous or reliable or not), she fulfils her proper function; but, when a person believes in accordance with virtuous or reliable dispositions, she fulfils her proper function with excellence. Thus, even if faith weren't reliable or virtuous, it could contribute at least to epistemic appropriateness, as B insists.

So, there is good reason to believe that a thesis in the neighbourhood of thesis D is correct. And, given this result, the epistemic disposition model of faith not only accommodates the idea that faith might explain the presence of religious belief, but that faith might explain the

adequate. But pursuing this end would take us too far afield in this paper.

${ }^{13}$ One reason why the internalist might object in this way is that allowing dispositions of which one is unaware to contribute to epistemic appropriateness will conflict with the subject's perspective objection. This objection, originally discussed in (Bonjour 1980), is that accounts which allow beliefs the truth of which would be an accident from the subject's perspective to be appropriate must be wrong. If $\mathrm{D}$ allows dispositions of which one is unaware to contribute to epistemic appropriateness, then it will allow for attitudes whose truth would be an accident from the subject's perspective to be appropriate.

${ }^{14}$ If we make use of virtues, the account may resemble (Zagzebski 1996) or (Sosa 2007b). If we make use of reliability, the account may resemble (Goldman 1979).

${ }^{15}$ Aquinas, from whom I have derived much inspiration for the present model, is one famous defender of the claim that faith is a virtue - a theological virtue. 
appropriateness of religious belief. Since other models of faith cannot do this, we have here a first attractive feature of the epistemic disposition model which favours it over other models.

\section{FAITH AND EVIDENCE, FAITH AND VOLITION, AND FAITH AND DOUBT}

In this section, I want to discuss a second attractive feature of the epistemic disposition model: it accommodates a variety of historically significant perspectives concerning the relationships between faith and evidence, faith and volition, and faith and doubt.

What I mean by this claim is the following. The general model of faith outlined above can be filled in so as to yield more narrow accounts of faith friendly toward a variety of different and opposing answers to significant questions about the relationships between faith and evidence, faith and volition, and faith and doubt. For example, if someone is attracted to the view that faith requires sufficient evidence and doesn't go beyond it, then she can fill in the general model above so as to yield an account of faith friendly toward that perspective. Or, on the other hand, if someone is attracted to the view that faith necessarily goes beyond the evidence, then she can fill in the general model above so as to yield an account of faith friendly toward this perspective. And similarly for questions about faith and volition and faith and doubt.

This is an attractive feature of the present general model, I contend. For, what we want is a model of religious faith which makes sense of the significant debates about these relationships which have endured through the centuries. If our general model of faith makes answering questions about these relationships easy, then there is a problem with our model. Thus, the fact that the general epistemic disposition model does not rule out historically significant perspectives about these relationships is another positive feature in favour of the model. Modelling faith in this way allows us to make sense of these significant debates. What has been going on in such debates is that we have been debating how to fill in the details of the general model of faith proposed here.

I take it, then, that if the present model does accommodate these various perspectives about faith, this is another positive feature in its favour. I will spend the rest of this section showing that the present model does accommodate these various perspectives. 
Begin with the relationship between faith and evidence. As I briefly mentioned above, there are at least two historically significant and opposing positions concerning the relationship between faith and evidence. On the one hand are those who think of faith as reasonable. In the extreme, this view has it that the person of faith holds her religious beliefs on the basis of publicly available evidence which adequately supports those beliefs. On this view, the person of faith does not go beyond what her evidence supports in holding her religious beliefs. Someone impressed with natural theology may be inclined toward a position like this. ${ }^{16}$ Opposing this view are accounts of faith according to which the person of faith goes significantly beyond reason in holding her religious beliefs. When she holds these beliefs, she doesn't do so on the basis of publicly available evidence which adequately supports those beliefs. Perhaps when she holds these beliefs, she isn't holding beliefs which her evidence disconfirms, but neither is she holding beliefs which her evidence confirms. By faith, she believes that which is not adequately supported by her evidence. ${ }^{17}$

The epistemic disposition model of faith can accommodate either of these perspectives about the relationship between faith and evidence. Someone who holds to the first perspective can narrow the realization conditions of faith so as to include only mental states whose content objectively confirms the propositions which the person is disposed by faith to believe. One way this may go is as follows. Many theistic arguments begin with some observation and argue that, given this observation, it is very likely or even necessary that some proposition of religious significance is true. The person of faith may be the one who is disposed, upon believing these observation claims, to believe the relevant propositions of religious significance. For instance, she may be disposed upon believing that everything with a beginning has a cause, to believe that God is the creator of the universe. The natural theologian would insist that when the person of faith here believes that God is the creator of the universe, she does so on the basis of evidence which objectively confirms that judgment - the observation that everything with a beginning has a cause. This will be so even if the person is ignorant

\footnotetext{
${ }^{16}$ See, e.g., (Swinburne 2005).

17 This perspective is embraced to varying degrees by philosophers as diverse as Plantinga (2000) and Hick (1989). It is, of course, associated with the Kierkegaardian tradition as well - see (Evans 1985).
} 
of the argument from the one claim to the other, that is, ignorant of the work of the natural theologian. Thus, by requiring that the realization conditions of faith objectively confirm the propositions which the person of faith is disposed by her faith to believe, someone attracted to this first perspective about the relationship between faith and evidence can specify the epistemic disposition model to accommodate her perspective.

On the other side, the person who believes that the person of faith goes beyond the evidence in holding her religious beliefs can also specify the epistemic disposition model to accommodate her perspective. She simply will not impose a requirement that the realization conditions of faith include only mental states whose content objectively confirms the propositions which the person of faith is disposed to believe. Indeed, if she wished, she could make these realization conditions rather all-inclusive. On this extreme version of the view, faith would be a disposition to believe propositions of religious significance pretty well no matter what mental states one finds oneself in. Here the person of faith is surely going quite beyond her evidence when she holds her religious beliefs.

Move to the second relationship - that between faith and volition. On one side of this issue are those who claim that holding religious beliefs by faith involves a significant volitional component. The person of faith takes a leap when she accepts her religious beliefs, and her leaping is very much up to her. ${ }^{18}$ She makes a decision, by faith, to take on these commitments. On the other side are those who emphasize that faith is a gift infused in the religious believer by a source outside of herself, and that the person who believes by faith deserves no credit for believing as she does. On this view, believing by faith involves little if any volitional element. The person of faith simply finds herself being drawn to her religious beliefs and then believing them. ${ }^{19}$

Again, the epistemic disposition model can accommodate either of these perspectives. Take the view according to which believing by faith does involve a significant volitional element first. Someone attracted to this perspective might further specify the epistemic disposition model by making it clear that faith is a resistible disposition. It is like a disposition I recently discovered that I have concerning gelato. On a recent visit to Italy, I learned that I have a disposition upon seeing gelato for sale after

\footnotetext{
${ }^{18}$ Evans (1985) provides an example of this view, as of course does William James (1896).

${ }^{19} \mathrm{I}$ am thinking here primarily of persons within the Calvinist or other theological determinist traditions.
} 
eating dinner to buy some. But, I also learned that, thankfully, this is a resistible disposition. I don't have to cave in. Though seeing the gelato does incline me to buy some, I can exercise my executive decision-making power and say "no." Someone who thinks that believing by faith involves a significant volitional element may wish to say the same about faith. Faith is a disposition to believe propositions of religious significance. But it is a resistible disposition. The person who has faith can say "no". Or, she can take a leap and say "yes". Faith encourages the leap, and it may even be that everyone who has faith takes the leap, but faith doesn't determine the leap..$^{20}$

On the other side, someone who wishes to maintain that believing by faith is not radically up to us may wish to maintain that faith is an irresistible disposition. It is like my disposition upon falling forward to stick out my hands in order to prevent falling flat on my face. I'm disposed to behave this way when I fall forward. And, since it happens as such a gut reaction of mine, I can't do anything to resist it - it has the status of a reflex. We might say the same about faith, maintaining that the person of faith is irresistibly disposed to believe. It's as if she has received a new nature and that believing is simply reflex-like for this new nature.

Consider finally the relationship between faith and doubt. According to some, the person of faith cannot have any doubts about her religious convictions. She believes them with absolute subjective certainty. Anything less than this would be less than a full religious commitment. ${ }^{21}$ Others maintain that faith is not incompatible with doubt. The person of faith may say, "I believe. Help my unbelief." She may even go through extended periods of time where her religious convictions are rather faint before returning to a more confident belief.

Unsurprisingly, the epistemic disposition model may be developed so as to accommodate either of these perspectives as well. Someone who wishes to maintain that faith rules out doubt can specify that the attitudes toward propositions of religious significance which faith disposes one to take must be attitudes implying subjective certainty. Someone who is only disposed to hold religious convictions faintly, on this view, will not have faith. On the other side, someone who wishes to allow that faith and doubt are compatible can specify that the attitudes toward which faith

\footnotetext{
${ }^{20}$ For a recent defence of the idea that dispositions may explain and encourage behaviour without determining it in a sense that eliminates free choice, see (O'Connor 2009).

${ }^{21} \mathrm{Al}$-Ghazali (2001) and Tennant (1989) furnish examples of this perspective.
} 
disposes someone needn't imply subjective certainty. Someone who is disposed to believe, even perhaps with a low degree of confidence, can still have faith on this picture.

This is a second feature which reflects well on the epistemic disposition model, then. This model can accommodate each of the above historically significant positions concerning the relationships between faith and evidence, faith and volition, and faith and doubt. The general model does not settle these important questions, and that is a positive feature of the model as a general model of how to understand religious faith. Since other models of faith do settle these questions, the present model is preferable to them insofar as they are offered as general models.

\section{RELIGIOUS FAITH AND OTHER TYPES OF FAITH}

Thus far I have presented the epistemic disposition model of faith and shown that it has two significant advantages over other contemporary models of faith. There are other features of the epistemic disposition model which are surely worthy of investigation. For instance, it would be profitable to discuss how this model accommodates the idea that a person might grow in her faith, and how it accommodates the idea that persons can be saved in a religious sense through their faith. But I can only do so much here. I'll close by discussing one more feature of the present model - its implications concerning the relationship between religious faith and other types of faith.

We use the term "faith" in many contexts other than religious ones. We say, for instance, that a wife has "faith" in her husband's marital faithfulness to her. We say that a player has "faith" in his teammates. We say that we have "faith" in our abilities. We say that we have "faith" in some authority. It would be desirable for a model of faith to explain how these various uses might be unified. The present model of religious faith as an epistemic disposition, I believe, can very easily explain how these uses are unified, whereas other models fail at this.

The epistemic disposition model of religious faith has it that faith is an epistemic disposition to take certain attitudes toward propositions of religious significance. A very natural way to extend this model to other domains would be as follows. Faith in whatever domain $\mathrm{D}$ is an epistemic disposition to take certain attitudes toward propositions of significance in domain $\mathrm{D}$. Thus, for instance, faith in one's teammate is an epistemic disposition to take certain attitudes toward propositions of significance 
concerning team sports. Faith in one's abilities is an epistemic disposition to take certain attitudes toward propositions of significance concerning one's abilities. Faith in an authority is an epistemic disposition to take certain attitudes toward propositions concerning which this authority has testified. And so on. Faith, in whatever domain, is an epistemic disposition to take attitudes toward propositions of significance in that domain.

In this way, we can explain how our talk of faith in various domains is unified. And, further, it is clear upon reflection that the accounts of faith in these various domains yielded by extending the epistemic disposition model are quite attractive accounts of faith in those domains. I'll illustrate this by focusing on the merits of the epistemic disposition model as it is applied to faith in oneself and faith in authorities.

There has been a surge of interest in the way in which trust in oneself and in the testimony of others works in recent epistemology. ${ }^{22}$ Much has been written concerning whether and when trusting oneself and trusting others is appropriate, and concerning how such trust might contribute to which attitudes are appropriate for one to take. It has become widely accepted that trusting oneself is an unavoidable rational requirement. And it has been argued that if trusting oneself is a rational requirement then so is trusting others, in the absence of defeaters. Interestingly, trust of these types is sometimes described using the language of faith. ${ }^{23}$

But while much has been said concerning whether and when trusting or having faith is appropriate and concerning how trusting might contribute to which attitudes are appropriate for a person to take, less has been said concerning the basic nature of trusting or having faith. And, regrettably, some recent and quick treatments of this topic are a it wanting. One common mistake is to treat faith or trust as a kind of meta-belief. Trust in oneself is treated as believing that one is a reliable believer, while trust in another is treated as believing that the other is a reliable testifier. ${ }^{24}$ But this sort of account is surely wrong, because persons who don't yet have a concept of reliability can still trust. And, more sophisticated believers can trust even if they believe a person is

${ }^{22}$ See, e.g., (Fricker 1995), (Goldman 2001), (Foley 2001), and (Koenig and Harris 2007).

${ }^{23}$ This is especially so for Foley (2001).

${ }^{24}$ Linda Zagzebski presented a view like this at the 2011 International Philosophy of Religion Conference in Krakow, Poland, in preparation for her upcoming Oxford Wilde Lectures. 
rather unreliable. In fact this isn't so uncommon. A person may know full well that an acquaintance has failed to make good on his promises in the past, but when he sincerely insists this one last time that he really will do what he says, she may trust him despite his unreliability. Some other model of trust in oneself and in others is therefore needed.

I propose that the models of these inspired by the epistemic disposition model of religious faith will do quite well. Rather than saying that faith or trust in another is a meta-belief about reliability, we should say that faith in another is an epistemic disposition to believe what the other testifies. Faith in oneself is similarly not a meta-belief about one's reliability, but a disposition to believe that to which one's faculties testify. The person who has faith in herself is disposed to believe that which seems right to her, whereas the person who has faith in another is disposed to believe that to which the other testifies. This faith may be more or less strong, depending upon the circumstances which serve as the realization conditions of the disposition. Unwavering trust in another would be a disposition to believe what the other says no matter what evidence one might possess to the contrary. We might have similar unwavering trust in certain of our faculties.

The epistemic disposition model of religious faith can therefore be extended to provide attractive accounts of faith in other domains. And there is a straightforward explanation of what unifies these diverse manifestations of faith. That the present model of religious faith yields such an explanation of the relationship between religious faith and other kinds of faith is just one more positive feature in its favour.

And it is a positive feature which other proposals fail to have. For, according to many contemporary models, what makes faith faith is simply its content - usually a religious content. Faith is conceived of as simply religious belief or perhaps religious knowledge. ${ }^{25}$ But such models fail to explain the relationship between religious faith and other kinds of faith. ${ }^{26}$ The present model does not fail to do this, but does it quite well. Thus, the present model is favourable to these.

\section{CONCLUSION}

In this paper, I introduced and explained the epistemic disposition model of religious faith. I argued that this model has three attractive

${ }^{25}$ (Plantinga 2000) would provide an example of the latter model of faith.

${ }^{26}$ This objection to these models is pressed at length in (Bishop 2010). 
features which favour it over competing models of religious faith. First, it accommodates the ideas that religious faith might explain the presence and appropriateness of religious belief. Second, it is amenable to a variety of historically significant perspectives concerning the relationships between faith and evidence, faith and volition, and faith and doubt. Finally, it yields an attractive explanation of the relationship between religious faith and other kinds of faith. For these reasons, I recommend the present model to anyone working on the concept of faith.

\section{BIBLIOGRAPHY}

al-Ghazâlî. 2001. Deliverance from Error and Mystical Union with the Almighty: Al-Munquidh Min Al-Dalâl, G. F. McLean, trans. (Washington DC: Council for Research in Values and Philosophy)

Alson, William. 1996. "Belief, acceptance, and religious faith", in J. Jordan and

D. Howard-Snyder (eds.), Faith, Freedom, and Rationality: Philosophy of Religion Today (London: Rowman \& Littlefield)

Audi, Robert. 1994. "Dispositional Beliefs and Dispositions to Believe", Nous 28 Bishop, John. 2010. "Faith", In Stanford Encyclopedia of Philosophy, ed. Edward N. Zalta. Available online at URL $=<\mathrm{http} / / /$ plato.stanford.edu/entries/faith/> Bishop, John. 2007. Believing by Faith: An Essay in the Epistemology and Ethics of Religious Belief (Oxford: Clarendon Press)

Bonjour, Lawrence. 1980. "Externalist Theories of Empirical Knowledge", Midwest Studies in Philosophy 5

Conee, Earl and Feldman, Richard. 2008. "Evidence", In Epistemology; New Essays, ed. Quentin Smith (New York: Oxford University Press)

Evans, C. Stephen. 1985. Philosophy of Religion: Thinking About Faith (Downers Grove IL: InterVarsity Press)

Fara, Michael. 2006. "Dispositions", In Stanford Encyclopedia of Philosophy, ed. Edward N. Zalta. Available online at URL $=<$ http://plato.stanford.edu/ entries/dispositions/>

Foley, Richard. 1983. "Epistemic Conservatism", Philosophical Studies 43

Foley, Richard. 2001. Intellectual Trust in Oneself and Others (Cambridge: Cambridge University Press)

Fricker, Elizabeth. 1995. "Telling and Trusting: Reductionism and AntiReductionism in the Epistemology of Testimony", Mind 104 (414)

Goldman, Alvin. 1979. "What is Justified Belief?", Reprinted in Epistemology: An Anthology, ed. Ernest Sosa and Jaegwon Kim (Malden: Blackwell, 2000) Goldman, Alvin. 2001. "Experts: Which Ones Should You Trust?", Philosophy and Phenomenological Research LXIII (1) 
Hajek, Alan. 2009. "Interpretations of Probability", In Stanford Encyclopedia of Philosophy, ed. Edward N. Zalta. Available online at URL $=<$ http://plato. stanford.edu/entries/probability-interpret/>

Hick, John. 1989. An Interpretation of Religion: Human Responses to the Transcendent (New Haven, CT: Yale University Press)

Huber, Franz and Schmidt-Petri, Christoph eds. 2009. Degrees of Belief (New York: Springer) James, William, 1896/1956. The Will to Believe and Other Essays in Popular Philosophy, and Human Immortality (New York: Dover)

Koenig, M. A. and P. L. Harris. 2007. "The Basis of Epistemic Trust: Reliable Testimony or Reliable Sources?”, Episteme 4(3)

Kvanvig, Jonathan. 1989. "Conservatism and its Virtues", Synthese 79

McGrath, Matthew. 2007. "Memory and Epistemic Conservatism", Synthese 157 O'Connor, Timothy. 2009. "Agent-Causal Power", in Dispositions and Causes, ed. Toby Handfield (New York: Oxford University Press)

Plantinga, Alvin. 2000. Warranted Christian Belief (New York: Oxford University Press)

Sosa, Ernest 2007a. "Intuitions: their Nature and Epistemic Efficacy", Grazer Philosophische Studien 74, no.1

Sosa, Ernest. 2007b. A Virtue Epistemology: Apt Belief and Reflective Knowledge, Volume 1 (New York: Oxford University Press)

Swinburne, Richard. 2001. Epistemic Justification (Oxford: Clarendon Press)

Swinburne, Richard. 2005. Faith and Reason, 2nd ed. (Oxford: Oxford University Press)

Tennant, F.R., 1943. The Nature of Belief (London: Centenary Press)

Vahid, Hamid. 2004. "Varieties of Epistemic Conservatism", Synthese 141

Williamson, Timothy. 2000. Knowledge and its Limits (New York: Oxford University Press)

Yaffe, Gideon and Nichols, Ryan. 2009. “Thomas Reid”, in Stanford Encyclopedia of Philosophy, ed. Edward N. Zalta. Available online at URL $=<$ http://plato. stanford.edu/entries/reid/>

Zagzebski, Linda. 1996. Virtues of the Mind (Cambridge: Cambridge University Press) 